\title{
An Improved Brain Mr Image Segmentation using Truncated Skew Gaussian Mixture
}

\author{
Nagesh Vadaparthi \\ Department of Information \\ Technology \\ MVGR College of Engineering \\ Vizianagaram, India
}

\author{
Srinivas Yerramalle \\ Department of Information \\ Technology \\ GIT, GITAM University \\ Visakhapatnam, India
}

\author{
Suresh Varma Penumatsa \\ Department of Computer Science \& \\ Engineering \\ Adikavi Nannayya University \\ Rajahmundry, India
}

\begin{abstract}
A novel approach for segmenting the MRI brain image based on Finite Truncated Skew Gaussian Mixture Model using Fuzzy C-Means algorithm is proposed. The methodology is presented evaluated on bench mark images. The obtained results are compared with various other techniques and the performance evaluation is performed using Image quality metrics and Segmentation metrics.
\end{abstract}

Keywords-Truncated Skew Gaussian Mixture model; Segmentation; Image quality metrics; Segmentation metrics; Fuzzy C-Means clustering

\section{INTRODUCTION}

MRI segmentation plays a vital role in medical research and applications. MRI has wide range of advantages over other conventional imaging techniques since magnetization and radio waves are used instead of X-rays in making the detailed and cross-sectional images of the brain [1]. Various operations based on image processing were defined earlier on MR images. Among these, segmentation of brain images into sub-regions has enormous research and medical applications. These subregions are utilized in visualizing and analyzing the anatomical structures in the brain which help in neuro-surgical planning [2].

There are various conventional methods for MRI segmentation which require human interaction in terms of mentioning number of classes for obtaining accurate and reliable segmentation. Thus, it is necessary to derive new techniques for effective segmentation. Much of the emphasis has been given to the segmentation algorithm based on finite normal mixture models where each image is assumed to be a mixture of Gaussian distributions. But actually it is observed that the pixels are quantized through the brightness or contrast in the gray scale level (Z) at that point. It is also observed that the image regions have finite range of pixel intensities $(-\infty,+\infty)$ and may not be symmetric and Meso kurtic [3]. In this paper, to have an accurate modeling of the feature vector, finite truncated skew Gaussian is considered by assuming that the pixel intensities in the entire image follow a Finite Truncated Skew Gaussian distribution [4][5][6][7][8].

Hence, in order to segment more accurately Fuzzy CMeans algorithm is preferred because of the additional flexibility that allows the pixel to belong to multiple classes with varying degree of membership [9].
Thus, in this paper Fuzzy C-Means (FCM) clustering algorithm is considered for segmenting the image into number of regions and derive the model parameters. The obtained parameters are thus refined further using the EM algorithm.

The rest of the paper is organized as follows: section-2 explains about the FCM algorithm, section-3 deals with the concept of Finite Truncated Skew Gaussian distribution and section-4 handles the initialization of parameters. Section-5 shows the updating of parameters and section- 6 demonstrates the proposed segmentation algorithm. In section-7 the experimental results are discussed, section- 8 concludes the paper, the scope for further enhancement is proposed in section 9 of the paper.

\section{FuZZy C-Means Clustering Algorithm}

The first step in any segmentation algorithm is to divide image into different image regions. Many segmentation algorithms are presented in literature [10],[11],[12],[13],[14]. Among these techniques, medical image segmentation based on K-Means is mostly utilized [4]. But, the main disadvantage with K-Means is that, K-Means are slow in convergence and pseudo unsupervised learning that requires the initial value of K. Apart from K-Means, hierarchical clustering algorithm[5] is also used but even this algorithm shares similar arguments as the case of K-Means algorithm. Fuzzy C-Means clustering algorithm in considered, in order to identify the initial clusters. The algorithm for Fuzzy C-means clustering is presented below.

The FCM employs fuzzy partitioning such that a data point can belong to all groups with different membership grades between 0 and 1 and it is an iterative algorithm. The aim of FCM is to find cluster centers (centroids) that minimize a dissimilarity function. To accommodate the introduction of fuzzy partitioning, the membership matrix (U) is randomly initialized according to Equation (1). $\sum_{i=1}^{c} u_{i j}=1, \forall j=1, \ldots, n$

The dissimilarity function which is used in FCM is given Equation (2)

$$
J\left(U, c_{1}, c_{2}, \ldots, c_{c}\right)=\sum_{i=1}^{c} J_{i}=\sum_{i=1}^{c} \sum_{j=1}^{n} u_{i j}{ }^{m} d_{i j}{ }^{2}
$$


Where, uij is between 0 and 1 ;

$c_{i}$ is the centroid of cluster $i$;

$\mathrm{d}_{\mathrm{ij}}$ is the Euclidian distance between $\mathrm{i}^{\text {th }}$ centroid $\left(\mathrm{c}_{\mathrm{i}}\right)$ and $\mathrm{j}^{\text {th }}$ data point;

$\mathrm{m} \epsilon[1, \infty]$ is a weighting exponent.

To reach a minimum of dissimilarity function there are two conditions. These are given in Equation (3) and Equation (4).

$$
\begin{gathered}
c_{i}=\frac{\sum_{j=1}^{n} u_{i j}{ }^{m} x_{j}}{\sum_{j=1}^{n} u_{i j}{ }^{m}} \\
u_{i j}=\frac{1}{\sum_{k=1}^{c}\left(\frac{d_{i j}}{d_{k j}}\right)^{2 /(m-1)}}
\end{gathered}
$$

This algorithm determines the following steps.

Step-1:Randomly initialize the membership matrix (U) that has constraints in Equation (1).

Step-2: Calculate centroids $\left(\mathrm{c}_{\mathrm{i}}\right)$ by using Equation (3).

Step-3:Compute dissimilarity between centroids and data points using equation (2). Stop if itsimprovement over previous iteration is below a threshold.

Step-4: Compute a new U using Equation (4). Go to Step 2.

By iteratively updating the cluster centers and the membership grades for each data point, FCM iteratively moves the cluster centers to the "right" location within a data set. FCM does not ensure that it converges to an optimal solution. Because of cluster centers (centroids) are initialized using $\mathrm{U}$ that randomly initialized (Equation (3)).

Performance depends on initial centroids. For a robust approach there are two ways which is described below.

1) Using an algorithm to determine all of the centroids (for example: arithmetic means of all data points).

2) Run FCM several times each starting with different initial centroids.

\section{Finite TrunCATED Skew Gaussian Distribution}

In any medical image, pixel is used as a measure of quantification and the entire medical image is assumed as a heterogeneous collection of pixels and each pixel is influenced by various factors such as brightness, contrast, saturation etc. For effectual analysis and classification of the brain tissues, it is obligatory to uphold good contrast between white matter and grey matter, but in general the grey matter structure consists of tissues with varying intensities compared to that of white matter, thereby making it a challenging task for effective classification of tissues in these regions.

A further issue associated is the problem of partial volume, many models assume that the pixels inside a particular tissue have homogenous properties, and follow a symmetric pattern and with this very assumption, the classification process is carried out. But in reality, white matter regions contain certain portion of grey matter at the boundaries and the tissues within these regions are assumed to contain the pixels having the probabilities which may be both symmetric and non-symmetric [5]. The problem gets multifold in case of abnormal brains, since registering these images with prior probabilities is difficult, as each pixel inside a region may belongs to a different class.

The effect of partial volume is due to the assumption of considering the distribution of the pixels inside the image regions as normal. Hence it is necessary to consider asymmetric distributions as the brain can diverge from the symmetric population, in order for it to be segmented satisfactorily.

The crucial information regarding the deformities in the brain can be available from the segmented regions, which may be skewed. In most of the brain related data, the information about the damaged tissues may be located at the boundaries (outliers) and the pixels inside these regions may exhibit non homogenous features, which include asymmetry, multimodality exhibiting long tails.

Hence to have an effective analysis about the damaged tissues, one need to consider mixture models which can accommodate data having non-normal features. Notable distribution among such models include the skew normal mixture model [15][16], the skew $\mathrm{t}$-mixture model [17][18][19], the skew $t$-normal mixture model [20], and some other non-elliptical approaches [21][22][23]. The log-Normal, the Burr, the Weibull the Gamma and the Generalized Pareto distribution are also considered in the literature for analyzing asymmetric data. Among these models, to model the data having long tails efficiently Skew Gaussian Mixture models are more appropriate [24][25][26].

Skew symmetric distributions are mainly used for the set of images where the shape of image regions are not symmetric or bell shaped distribution and these distributions can be well utilized for the medical images where the bone structure of the humans are asymmetric in nature. To have a more accurate analysis of the medical images, it is customary to consider that in any image, the range of the pixels is finite in nature. Among the pixels generated from the brain images, to extract the features effectively only finite ranges of pixels are very much useful. Hence, to have a more closure and deeper approximation of the medical data, truncated skew normal distribution are well suited

The probability density function of the truncated skew normal distribution is given by

$f_{\mu, \sigma, \lambda}(x)=\frac{2}{\sigma} \phi\left(\frac{x-\mu}{\sigma}\right) \cdot \Phi\left(\lambda \frac{x-\mu}{\sigma}\right)$

where, $\mu \in \mathrm{R}, \sigma>0$ and $\lambda \in \mathrm{R}$ represents the location, scale and shape parameters respectively. Where $\phi$ and $\boldsymbol{\Phi}$ denote the probability density function and the cumulative density function of the standard normal distribution.

The limits and of the truncated normal distribution are $\mathrm{Zl}$ $=\mathrm{a}$ and $\mathrm{Zm}=\mathrm{b}$. Where $\mathrm{Zl}$ and $\mathrm{Zm}$ denotes the truncation limits. 
Truncating equation (1) between these limits, the following equations are obtained

$F_{\mu, \sigma, \lambda}(x) \int_{a}^{b}=F_{\mu, \sigma, \lambda}(b)-F_{\mu, \sigma, \lambda}(a)$

where,

$F_{\mu, \sigma, \lambda}(a)=\int_{-\infty}^{a} F_{\mu, \sigma, \lambda}(x) d x$

and

$F_{\mu, \sigma, \lambda}(b)=\int_{-\infty}^{b} F_{\mu, \sigma, \lambda}(x) d x$

where,

$\mathrm{f} \mu, \sigma, \lambda(\mathrm{x})$ is as given in equation (1)

$Q=\int_{-\infty}^{b} \frac{2}{\sigma} \varphi\left(\frac{x-\mu}{\sigma}\right) \bar{\varphi}\left(\frac{\lambda(x-\mu)}{\sigma}\right) d x-\int_{-\infty}^{a} \frac{2}{\sigma} \varphi\left(\frac{x-\mu}{\sigma}\right) \bar{\varphi}\left(\frac{\lambda(x-\mu)}{\sigma}\right) d x(9)$

\section{INITIALIZATION OF PARAMETERS}

In order to initialize the parameters, it is needed to obtain the initial values of the model distribution. The estimates of the Mixture model $\mu \mathrm{i}, \sigma \mathrm{i}$ and $\alpha \mathrm{i}$ where $\mathrm{i}=1,2 . ., \mathrm{k}$ are estimated using Fuzzy C-Means Clustering algorithm as proposed in section-II. It is assumed that the pixel intensities of the entire image is segmented into a $\mathrm{K}$ component model $\pi \mathrm{i}, \mathrm{i}=1,2 \ldots \mathrm{K}$ with the assumption that $\pi \mathrm{i}=1 / \mathrm{K}$ where $\mathrm{K}$ is the value obtained from Fuzzy C-Means Clustering algorithm discussed in section-2.

\section{UPDATING INITIAL Estimates THROUGH EM ALGORITHM}

The initial estimates of $\mu \mathrm{i}, \sigma \mathrm{i}$ and $\alpha \mathrm{i}$ that are obtained from section -4 are to be refined to obtain the final estimates. For this purpose EM algorithm is utilized. The EM algorithm consists of 2 steps E-step and M-Step. In the E-Step, the initial estimates obtained in section -4 are taken as input and the final updated equations are obtained in the M-Step. The updated equations for the model parameters $\mu, \sigma$ and $\alpha$ are given below.

$\mu^{l+1}=\frac{\int_{-\infty}^{\mathrm{b}} \mathrm{x} \cdot \varphi\left(\frac{\mathrm{x}-\mu}{\sigma}\right) \bar{\varphi}^{\prime}\left(\frac{\alpha(\mathrm{x}-\mu)}{\sigma}\right) \mathrm{dx}-\int_{-\infty}^{\mathrm{a}} \mathrm{x} \cdot \varphi\left(\frac{\mathrm{x}-\mu}{\sigma}\right) \bar{\varphi}^{\prime}\left(\frac{\alpha(\mathrm{x}-\mu)}{\sigma}\right) \mathrm{dx}}{\int_{-\infty}^{\mathrm{b}} \varphi\left(\frac{\mathrm{x}-\mu}{\sigma}\right) \bar{\varphi}^{\prime}\left(\frac{\alpha(\mathrm{x}-\mu)}{\sigma}\right) \mathrm{dx}-\int_{-\infty}^{\mathrm{a}} \varphi\left(\frac{\mathrm{x}-\mu}{\sigma}\right) \bar{\varphi}^{\prime}\left(\frac{\alpha(\mathrm{x}-\mu)}{\sigma}\right) \mathrm{dx}}$
$\propto^{l+1}=-\frac{\int_{-\infty}^{\mathrm{b}} \varphi^{\prime}\left(\frac{\mathrm{x}-\mu}{\sigma}\right) \bar{\varphi}\left(\frac{\alpha(\mathrm{x}-\mu)}{\sigma}\right) \mathrm{dx}-\int_{-\infty}^{\mathrm{a}} \varphi^{\prime}\left(\frac{\mathrm{x}-\mu}{\sigma}\right) \bar{\varphi}\left(\frac{\alpha(\mathrm{x}-\mu)}{\sigma}\right) \mathrm{dx}}{\int_{-\infty}^{\mathrm{b}} \varphi\left(\frac{\mathrm{x}-\mu}{\sigma}\right) \bar{\varphi}^{\prime}\left(\frac{\alpha(\mathrm{x}-\mu)}{\sigma}\right) \mathrm{dx}-\int_{-\infty}^{\mathrm{a}} \varphi\left(\frac{\mathrm{x}-\mu}{\sigma}\right) \bar{\varphi}^{\prime}\left(\frac{\alpha(\mathrm{x}-\mu)}{\sigma}\right) \mathrm{dx}}$

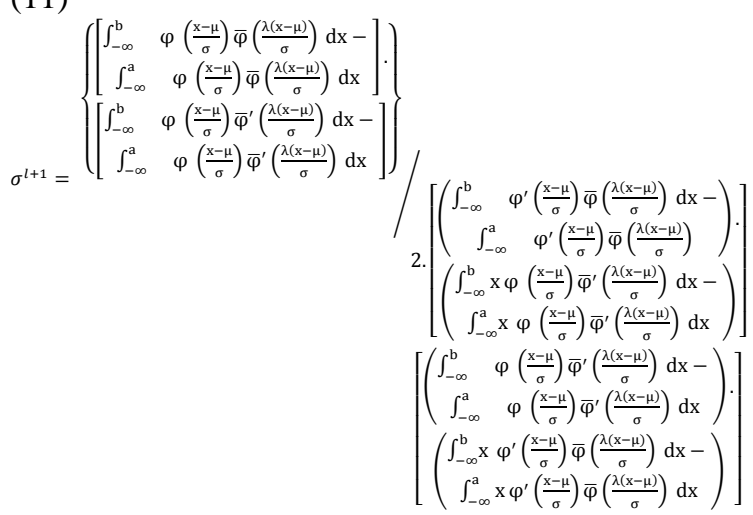

\section{SEgMENTATION ALgORITHM}

After refining the estimates, the important step is to convert the heterogeneous data into homogenous data or group the related pixels. This process is carried out by performing the segmentation. The image segmentation is done in 3 steps:

Step-1: Obtain the initial estimates of the finite truncated skew Gaussian mixture model using Fuzzy C-Means Clustering algorithm.

Step-2: Using the initial estimates obtained from step-1, the EM algorithm is iteratively carried out.

Step-3: The image segmentation is carried out by assigning each pixel into a proper region (Segment) according to maximum likelihood estimates of the $\mathrm{jth}$ element $\mathrm{Lj}$ according to the following equation

$$
\begin{gathered}
L_{j}=\operatorname{Max}_{j}\left\{\int_{-\infty}^{\mathrm{b}} \frac{2}{\sigma} \varphi\left(\frac{\mathrm{x}-\mu}{\sigma}\right) \bar{\varphi}\left(\frac{\lambda(\mathrm{x}-\mu)}{\sigma}\right) \mathrm{dx}-\int_{-\infty}^{\mathrm{a}} \frac{2}{\sigma} \varphi\left(\frac{\mathrm{x}-\mu}{\sigma}\right) \bar{\varphi}\left(\frac{\lambda(\mathrm{x}-\mu)}{\sigma}\right) \mathrm{dx}\right\} \\
\text { VII. EXPERIMENTAL RESULTS \& PERFORMANCE } \\
\text { EVALUATION }
\end{gathered}
$$

In order to evaluate the performance of the developed algorithm, T1 weighted images were used. The input medical images are obtained from brain web images. It is assumed that the intensities of the pixels in medical images are asymmetric in nature. Hence, follow a skew Gaussian distribution and as the limits are finite and within the specified range of values are only necessary in medical image segmentation process Truncated skew Gaussian distribution. Is used The initialization of parameters for each segment is achieved by using Fuzzy C-Means Clustering algorithm and the estimates are updated using the EM algorithm. The experimentation is carried out by using the segmentation algorithm depicted in section- 6 and the obtained results are evaluated using segmentation quality metrics[27] such as Jacquard Coefficient (JC), Volumetric Similarity (VS), Variation of Information (VOI), Probabilistic Rand Index (PRI) and Global Consistency Error (GCE) and the formulas for calculating these metrics are given as follows:

Jaccord Coefficient (JC) $=\frac{|X \cap Y|}{|X \cup Y|}=\frac{\mathrm{a}}{\mathrm{a}+\mathrm{b}+\mathrm{c}}$

Volume Similarity (VS) $=1-\frac{|| X|-| Y||}{|X|+|Y|}=1-\frac{|b-c|}{2 a+b+c}$

Where, $\quad \mathrm{a}=|\mathrm{X} \cap \mathrm{Y}|, \mathrm{b}=|\mathrm{X} / \mathrm{Y}|, \quad \mathrm{c}=|\mathrm{Y} / \mathrm{X}|, \quad \mathrm{d}=|\overline{X \cup Y}|$

$\operatorname{GCE}\left(\mathrm{S}, \mathrm{S}^{\prime}\right)=\frac{1}{\mathrm{~N}} \min \left\{\sum \operatorname{LRE}\left(\mathrm{S}, \mathrm{S}^{\prime}, \mathrm{x}_{\mathrm{i}}\right), \sum \operatorname{LRE}\left(\mathrm{S}^{\prime}, \mathrm{S}, \mathrm{x}_{\mathrm{i}}\right)\right\}$

Where, LRE $=\frac{\left|C\left(S, \mathrm{x}_{\mathrm{i}}\right) \backslash C\left(S^{\prime}, \mathrm{x}_{\mathrm{i}}\right)\right|}{\left|C\left(S, \mathrm{x}_{\mathrm{i}}\right)\right|} \mathrm{S}$ and $\mathrm{S}^{\prime}$ are segment classes and $\mathrm{x}_{\mathrm{i}}$ is the pixel.

$$
\text { VOI }(X, Y)=H(X)=H(Y)-2 I(X ; Y)
$$

Where, $\mathrm{X}$ and $\mathrm{Y}$ are two clusters

$$
\operatorname{PRI}\left(\mathrm{S}_{\mathrm{t}},\{\mathrm{S}\}\right)=\frac{1}{\left(\begin{array}{c}
N \\
2
\end{array}\right)} \sum_{i, j, i<j}\left[I\left(l_{i}^{S_{t}}=l_{j}^{S_{t}}\right) p_{j}+I\left(l_{i}^{S_{t}} \neq l_{j}^{S_{t}}\right)\left(1-p_{j}\right)\right]
$$

Where, $p_{j}=P\left(l_{i}=l_{j}\right)=\frac{1}{K} \sum_{k=1}^{K} I\left(l_{i}^{k}=l_{j}^{k}\right)$ and the values range from 0 to 1 . The value 1 denotes the segments are identical. 
TABLE I. SEGMENTATION QUALITY METRICS

\begin{tabular}{|c|c|c|c|c|c|c|c|c|c|c|}
\hline Image & $\begin{array}{l}\text { Quality } \\
\text { Metric }\end{array}$ & GMM & $\begin{array}{l}\text { Skew } \\
\text { GMM } \\
\text { with K- } \\
\text { Means- } \\
\text { EM } \\
\end{array}$ & $\begin{array}{l}\text { Truncated } \\
\text { SGMM } \\
\text { with K- } \\
\text { Means }\end{array}$ & $\begin{array}{l}\text { Skew } \\
\text { GMM } \\
\text { with } \\
\text { HC-EM }\end{array}$ & $\begin{array}{l}\text { Truncated } \\
\text { SGMM with } \\
\text { HC }\end{array}$ & $\begin{array}{l}\text { Skew } \\
\text { GMM } \\
\text { with FCM } \\
\text {-EM }\end{array}$ & $\begin{array}{l}\text { Truncated } \\
\text { SGMM } \\
\text { with FCM }\end{array}$ & $\begin{array}{l}\text { Standard } \\
\text { Limits }\end{array}$ & $\begin{array}{l}\text { Standard } \\
\text { Criteria }\end{array}$ \\
\hline B0S1 & $\begin{array}{l}\text { JC } \\
\text { VS } \\
\text { VOI } \\
\text { GCE } \\
\text { PRI }\end{array}$ & $\begin{array}{l}0.089 \\
0.432 \\
2.3665 \\
0.2802 \\
0.504\end{array}$ & $\begin{array}{l}0.689 \\
0.733 \\
5.3173 \\
0.5964 \\
0.6396\end{array}$ & $\begin{array}{l}0.711 \\
0.781 \\
5.2323 \\
0.6088 \\
0.6697\end{array}$ & $\begin{array}{l}0.703 \\
0.8799 \\
5.142 \\
0.561 \\
0.619\end{array}$ & $\begin{array}{l}0.736 \\
0.887 \\
5.381 \\
0.626 \\
0.663\end{array}$ & $\begin{array}{l}0.795 \\
0.891 \\
5.232 \\
0.4223 \\
0.7958\end{array}$ & $\begin{array}{l}0.832 \\
0.923 \\
4.7099 \\
0.5025 \\
0.6009\end{array}$ & $\begin{array}{l}0 \text { to } 1 \\
0 \text { to } 1 \\
-\infty \text { to } \infty \\
0 \text { to } 1 \\
0 \text { to } 1\end{array}$ & $\begin{array}{l}\text { Close to } 1 \\
\text { Close to } 1 \\
\text { Possible } \\
\text { Big } \\
\text { Close to 1 } \\
\text { Close to 1 }\end{array}$ \\
\hline B0S2 & $\begin{array}{l}\text { JC } \\
\text { VS } \\
\text { VOI } \\
\text { GCE } \\
\text { PRI }\end{array}$ & $\begin{array}{l}0.0677 \\
0.3212 \\
1.9724 \\
0.2443 \\
0.416\end{array}$ & $\begin{array}{l}0.7656 \\
0.8767 \\
3.924 \\
0.4741 \\
0.5016\end{array}$ & $\begin{array}{l}0.7921 \\
0.8801 \\
0 \\
0 \\
1\end{array}$ & $\begin{array}{l}0.7921 \\
0.8814 \\
4.35 \\
0.419 \\
0.514\end{array}$ & $\begin{array}{l}0.812 \\
0.892 \\
4.63 \\
0.5013 \\
0.542\end{array}$ & $\begin{array}{l}0.819 \\
0.8914 \\
6.2894 \\
0.4664 \\
0.6847\end{array}$ & $\begin{array}{l}0.851 \\
0.923 \\
4.9823 \\
0.5125 \\
0.6506\end{array}$ & $\begin{array}{l}0 \text { to } 1 \\
0 \text { to } 1 \\
-\infty \text { to } \infty \\
0 \text { to } 1 \\
0 \text { to } 1\end{array}$ & $\begin{array}{l}\text { Close to 1 } \\
\text { Close to } 1 \\
\text { Possible } \\
\text { Big } \\
\text { Close to 1 } \\
\text { Close to 1 }\end{array}$ \\
\hline B0S3 & $\begin{array}{l}\text { JC } \\
\text { VS } \\
\text { VOI } \\
\text { GCE } \\
\text { PRI }\end{array}$ & $\begin{array}{l}0.0434 \\
0.123 \\
0.7684 \\
0.089 \\
0.576\end{array}$ & $\begin{array}{l}0.6567 \\
0.812 \\
0.2916 \\
0.031 \\
0.5853\end{array}$ & $\begin{array}{l}0.689 \\
0.849 \\
0 \\
0 \\
1\end{array}$ & $\begin{array}{l}0.7143 \\
0.916 \\
1.659 \\
0.107 \\
0.632\end{array}$ & $\begin{array}{l}0.722 \\
0.932 \\
2.956 \\
0.02 \\
0.661\end{array}$ & $\begin{array}{l}0.784 \\
0.926 \\
5.5318 \\
0.4001 \\
0.706\end{array}$ & $\begin{array}{l}0.818 \\
0.947 \\
4.3623 \\
0.3943 \\
0.7111\end{array}$ & $\begin{array}{l}0 \text { to } 1 \\
0 \text { to } 1 \\
-\infty \text { to } \infty \\
0 \text { to } 1 \\
0 \text { to } 1\end{array}$ & $\begin{array}{l}\text { Close to 1 } \\
\text { Close to 1 } \\
\text { Possible } \\
\text { Big } \\
\text { Close to 1 } \\
\text { Close to 1 }\end{array}$ \\
\hline B0S4 & $\begin{array}{l}\text { JC } \\
\text { VS } \\
\text { VOI } \\
\text { GCE } \\
\text { PRI }\end{array}$ & $\begin{array}{l}0.0456 \\
0.2233 \\
1.268 \\
0.056 \\
0.189\end{array}$ & $\begin{array}{l}0.7878 \\
0.3232 \\
1.569 \\
0.091 \\
0.191\end{array}$ & $\begin{array}{l}0.7891 \\
0.465 \\
0 \\
0 \\
1\end{array}$ & $\begin{array}{l}0.874 \\
0.54 \\
3.354 \\
0.157 \\
0.496\end{array}$ & $\begin{array}{l}0.896 \\
0.621 \\
3.693 \\
0.199 \\
0.519\end{array}$ & $\begin{array}{l}0.911 \\
0.643 \\
4.1619 \\
0.2949 \\
0.5628\end{array}$ & $\begin{array}{l}0.933 \\
0.722 \\
2.9053 \\
0.2554 \\
0.6987\end{array}$ & $\begin{array}{l}0 \text { to } 1 \\
0 \text { to } 1 \\
-\infty \text { to } \infty \\
0 \text { to } 1 \\
0 \text { to } 1\end{array}$ & $\begin{array}{l}\text { Close to 1 } \\
\text { Close to 1 } \\
\text { Possible } \\
\text { Big } \\
\text { Close to 1 } \\
\text { Close to 1 }\end{array}$ \\
\hline B1S1 & $\begin{array}{l}\text { JC } \\
\text { VS } \\
\text { VOI } \\
\text { GCE } \\
\text { PRI }\end{array}$ & $\begin{array}{l}0.141 \\
0.313 \\
1.6499 \\
0.1874 \\
0.9256\end{array}$ & $\begin{array}{l}0.776 \\
0.397 \\
4.0874 \\
0.4487 \\
0.6678\end{array}$ & $\begin{array}{l}0.779 \\
0.452 \\
3.9136 \\
0.4651 \\
0.7578\end{array}$ & $\begin{array}{l}0.791 \\
0.784 \\
3.951 \\
0.418 \\
0.6258\end{array}$ & $\begin{array}{l}0.8123 \\
0.797 \\
4.13 \\
0.4468 \\
0.6692\end{array}$ & $\begin{array}{l}0.826 \\
0.7910 \\
4.4115 \\
0.2752 \\
0.686\end{array}$ & $\begin{array}{l}0.861 \\
0.811 \\
3.5797 \\
0.4103 \\
0.8044\end{array}$ & $\begin{array}{l}0 \text { to } 1 \\
0 \text { to } 1 \\
-\infty \text { to } \infty \\
0 \text { to } 1 \\
0 \text { to } 1\end{array}$ & $\begin{array}{l}\text { Close to 1 } \\
\text { Close to 1 } \\
\text { Possible } \\
\text { Big } \\
\text { Close to 1 } \\
\text { Close to 1 }\end{array}$ \\
\hline B1S2 & $\begin{array}{l}\text { JC } \\
\text { VS } \\
\text { VOI } \\
\text { GCE } \\
\text { PRI }\end{array}$ & $\begin{array}{l}0.098 \\
0.0433 \\
2.3215 \\
0.2838 \\
0.3807\end{array}$ & $\begin{array}{l}0.7892 \\
0.878 \\
2.8047 \\
0.3407 \\
0.369\end{array}$ & $\begin{array}{l}0.7902 \\
0.898 \\
2.921 \\
0.348 \\
0.429\end{array}$ & $\begin{array}{l}0.877 \\
0.881 \\
3.91 \\
0.339 \\
0.485\end{array}$ & $\begin{array}{l}0.908 \\
0.896 \\
5.122 \\
0.3695 \\
0.561\end{array}$ & $\begin{array}{l}0.896 \\
0.918 \\
6.6411 \\
0.4661 \\
0.6322\end{array}$ & $\begin{array}{l}0.912 \\
0.931 \\
2.8047 \\
0.3407 \\
0.8690\end{array}$ & $\begin{array}{l}0 \text { to } 1 \\
0 \text { to } 1 \\
-\infty \text { to } \infty \\
0 \text { to } 1 \\
0 \text { to } 1\end{array}$ & $\begin{array}{l}\text { Close to } 1 \\
\text { Close to } 1 \\
\text { Possible } \\
\text { Big } \\
\text { Close to 1 } \\
\text { Close to 1 }\end{array}$ \\
\hline B1S3 & $\begin{array}{l}\text { JC } \\
\text { VS } \\
\text { VOI } \\
\text { GCE } \\
\text { PRI }\end{array}$ & $\begin{array}{l}0.0222 \\
0.3223 \\
1.2411 \\
0.1466 \\
0.9576\end{array}$ & $\begin{array}{l}0.8926 \\
0.3429 \\
0.9988 \\
0.1157 \\
0.9662\end{array}$ & $\begin{array}{l}0.899 \\
0.425 \\
1.252 \\
0.227 \\
0.856\end{array}$ & $\begin{array}{l}0.9124 \\
0.3543 \\
2.665 \\
0.398 \\
0.652\end{array}$ & $\begin{array}{l}0.9236 \\
0.359 \\
3.6351 \\
0.424 \\
0.698\end{array}$ & $\begin{array}{l}0.946 \\
0.3869 \\
6.7129 \\
0.4559 \\
0.7202\end{array}$ & $\begin{array}{l}0.969 \\
0.441 \\
0.9988 \\
0.1157 \\
0.9675\end{array}$ & $\begin{array}{l}0 \text { to } 1 \\
0 \text { to } 1 \\
-\infty \text { to } \infty \\
0 \text { to } 1 \\
0 \text { to } 1\end{array}$ & $\begin{array}{l}\text { Close to 1 } \\
\text { Close to 1 } \\
\text { Possible } \\
\text { Big } \\
\text { Close to 1 } \\
\text { Close to 1 }\end{array}$ \\
\hline B1S4 & $\begin{array}{l}\text { JC } \\
\text { VS } \\
\text { VOI } \\
\text { GCE } \\
\text { PRI }\end{array}$ & $\begin{array}{l}0.455 \\
0.329 \\
-8.8 \mathrm{e}- \\
16 \\
0.119 \\
0.065 \\
\end{array}$ & $\begin{array}{l}0.762 \\
0.7001 \\
0.201 \\
0.112 \\
0.1001\end{array}$ & $\begin{array}{l}0.797 \\
0.779 \\
1.332 \\
0.176 \\
0.129\end{array}$ & $\begin{array}{l}0.815 \\
0.7158 \\
0.19 \\
0.212 \\
0.27\end{array}$ & $\begin{array}{l}0.826 \\
0.754 \\
2.35 \\
0.265 \\
0.353\end{array}$ & $\begin{array}{l}0.854 \\
0.786 \\
5.0898 \\
0.3062 \\
0.5573\end{array}$ & $\begin{array}{l}0.889 \\
0.895 \\
5.561 \\
0.5214 \\
0.691\end{array}$ & $\begin{array}{l}0 \text { to } 1 \\
0 \text { to } 1 \\
-\infty \text { to } \infty \\
0 \text { to } 1 \\
0 \text { to } 1\end{array}$ & $\begin{array}{l}\text { Close to 1 } \\
\text { Close to } 1 \\
\text { Possible } \\
\text { Big } \\
\text { Close to 1 } \\
\text { Close to 1 }\end{array}$ \\
\hline
\end{tabular}



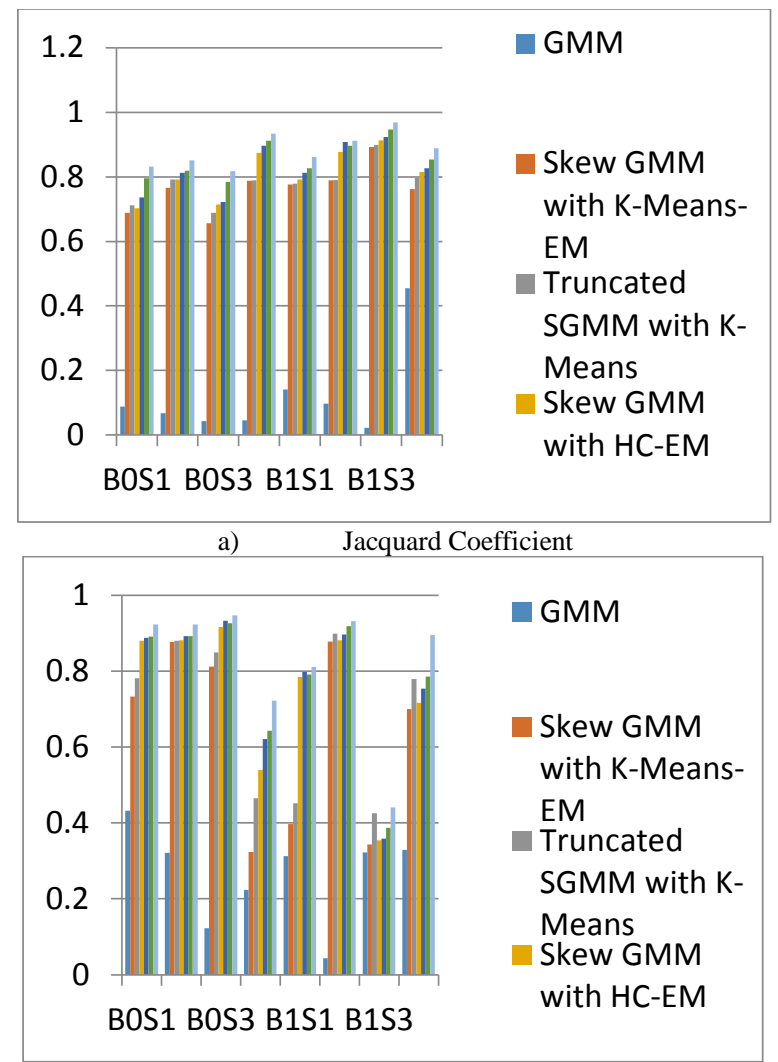

b) Volume Similarity

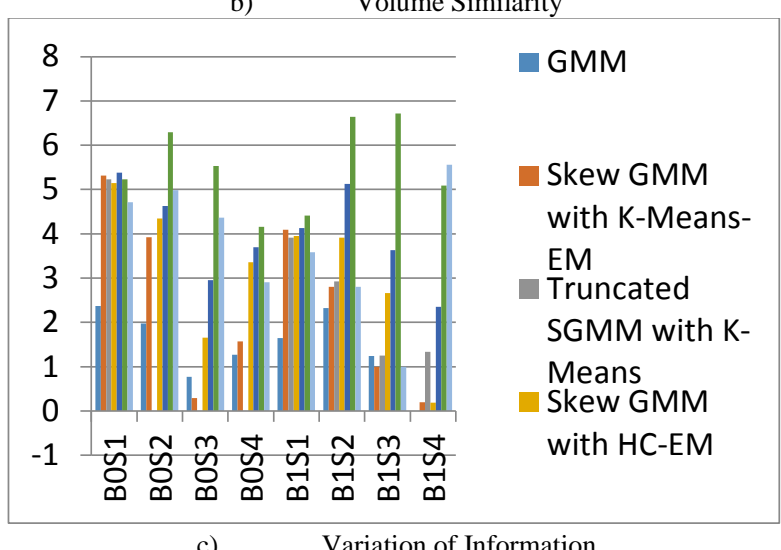

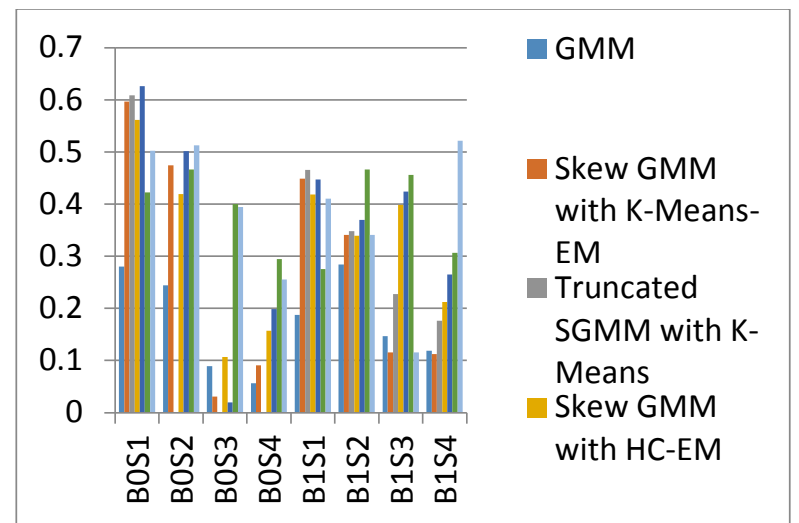

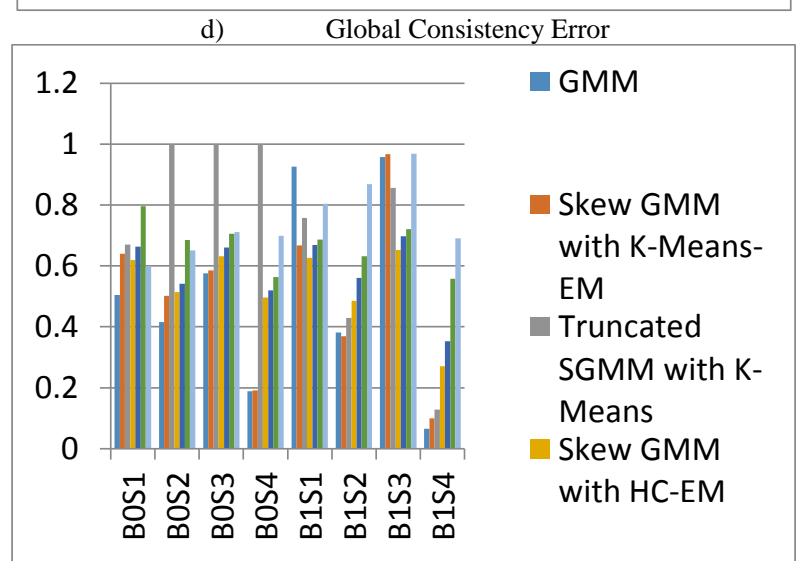

e) Probabilistic Rand Index

Fig. 1. Segmentation Quality Metrics

The reconstruction process is carried out by positioning each pixel into its appropriate location. The performance evaluation [27] of the obtained output is done using the image quality metrics such as Average difference, Maximum distance, Image Fidelity, Means Squared Error and Peak Signal-to-Noise ratio.

The developed algorithm is compared with Skew Gaussian mixture model with K-Means, Hierarchical Clustering, Fuzzy C-Means, Truncated Skew Gaussian mixture model with KMeans and Hierarchical Clustering algorithms and the results obtained are tabulated in Table-1, Table- 2 and fig.- $1 \&$ fig- 2 .

TABLE II. SEgmentation Quality MEtrics

\begin{tabular}{|c|c|c|c|c|c|c|c|c|c|c|}
\hline Image & $\begin{array}{l}\text { Quality } \\
\text { Metric }\end{array}$ & GMM & $\begin{array}{c}\text { Skew } \\
\text { GMM } \\
\text { with } \\
\text { K- } \\
\text { Means }\end{array}$ & $\begin{array}{c}\text { Truncated } \\
\text { SGMM } \\
\text { with K- } \\
\text { Means }\end{array}$ & $\begin{array}{c}\text { Skew } \\
\text { GMM } \\
\text { with HC }\end{array}$ & $\begin{array}{c}\text { Truncated } \\
\text { SGMM with } \\
\text { HC }\end{array}$ & $\begin{array}{c}\text { SGMM } \\
\text { with Fuzzy } \\
\text { CMean }\end{array}$ & $\begin{array}{c}\text { Truncated } \\
\text { SGMM } \\
\text { with FCM }\end{array}$ & $\begin{array}{l}\text { Standard } \\
\text { Limits }\end{array}$ & $\begin{array}{c}\text { Standard } \\
\text { Criteria }\end{array}$ \\
\hline B0S1 & $\begin{array}{c}\text { AD } \\
\text { MD } \\
\text { IF } \\
\text { MSE } \\
\text { SNR }\end{array}$ & $\begin{array}{c}0.573 \\
0.422 \\
0.416 \\
0.04 \\
17.41\end{array}$ & $\begin{array}{l}0.773 \\
0.922 \\
0.875 \\
0.134 \\
29.23\end{array}$ & $\begin{array}{c}0.792 \\
0.941 \\
0.428 \\
2.19 \mathrm{e}-005 \\
72.15\end{array}$ & $\begin{array}{c}0.812 \\
0.9325 \\
0.923 \\
0.094 \\
33.89\end{array}$ & $\begin{array}{c}0.835 \\
0.939 \\
0.941 \\
2.92 \mathrm{E}-005 \\
87.39\end{array}$ & $\begin{array}{c}0.8451 \\
0.945 \\
0.9756 \\
9.3 \mathrm{E}-07 \\
108.42\end{array}$ & $\begin{array}{c}0.899 \\
0.973 \\
0.9805 \\
3.03 \mathrm{e}-005 \\
93.324\end{array}$ & $\begin{array}{l}-1 \text { to } 1 \\
-1 \text { to } 1 \\
0 \text { to } 1 \\
0 \text { to } 1 \\
-\infty \text { to } \infty\end{array}$ & $\begin{array}{l}\text { Closer to } 1 \\
\text { Closer to } 1 \\
\text { Closer to } 1 \\
\text { Closer to 0 } \\
\text { Possible Big }\end{array}$ \\
\hline & & & & & & & & & & \\
\hline
\end{tabular}


(IJACSA) International Journal of Advanced Computer Science and Applications,

Vol. 6, No. 7, 2015

\begin{tabular}{|c|c|c|c|c|c|c|c|c|c|c|}
\hline B0S2 & $\begin{array}{c}\text { AD } \\
\text { MD } \\
\text { IF } \\
\text { MSE } \\
\text { SNR }\end{array}$ & $\begin{array}{c}0.37 \\
0.221 \\
0.336 \\
0.240 \\
14.45\end{array}$ & $\begin{array}{l}0.876 \\
0.897 \\
0.876 \\
0.211 \\
35.65\end{array}$ & $\begin{array}{l}0.887 \\
0.910 \\
0.894 \\
0.124 \\
84.23\end{array}$ & $\begin{array}{c}0.749 \\
0.912 \\
0.859 \\
0.2019 \\
39.85\end{array}$ & $\begin{array}{l}0.798 \\
0.926 \\
0.873 \\
0.102 \\
89.65\end{array}$ & $\begin{array}{c}0.49 \\
0.931 \\
0.9046 \\
3.6 \mathrm{E}-06 \\
102.5\end{array}$ & $\begin{array}{c}0.921 \\
0.951 \\
0.991 \\
3.01 \mathrm{e}-005 \\
93.34\end{array}$ & $\begin{array}{l}-1 \text { to } 1 \\
-1 \text { to } 1 \\
0 \text { to } 1 \\
0 \text { to } 1 \\
-\infty \text { to } \infty\end{array}$ & $\begin{array}{l}\text { Closer to } 1 \\
\text { Closer to } 1 \\
\text { Closer to } 1 \\
\text { Closer to 0 } \\
\text { Possible Big }\end{array}$ \\
\hline B0S3 & $\begin{array}{c}\text { AD } \\
\text { MD } \\
\text { IF } \\
\text { MSE } \\
\text { SNR }\end{array}$ & $\begin{array}{c}0.456 \\
0.345 \\
0.44 \\
0.22 \\
19.88\end{array}$ & $\begin{array}{c}0.76 \\
0.879 \\
0.86 \\
0.23 \\
37.98\end{array}$ & $\begin{array}{c}0.796 \\
0.847 \\
0.883 \\
0.2012 \\
77.46\end{array}$ & $\begin{array}{c}0.81 \\
0.807 \\
0.917 \\
0.2123 \\
39.71\end{array}$ & $\begin{array}{c}0.826 \\
0.86 \\
0.919 \\
0.267 \\
82.31\end{array}$ & $\begin{array}{c}0.6721 \\
0.911 \\
0.9366 \\
2.43 \mathrm{E}-06 \\
104.27\end{array}$ & $\begin{array}{c}0.835 \\
0.947 \\
0.928 \\
3.55 \mathrm{e}-005 \\
92.63\end{array}$ & $\begin{array}{l}-1 \text { to } 1 \\
-1 \text { to } 1 \\
0 \text { to } 1 \\
0 \text { to } 1 \\
-\infty \text { to } \infty\end{array}$ & $\begin{array}{l}\text { Closer to } 1 \\
\text { Closer to } 1 \\
\text { Closer to } 1 \\
\text { Closer to 0 } \\
\text { Possible Big }\end{array}$ \\
\hline B0S4 & $\begin{array}{c}\text { AD } \\
\text { MD } \\
\text { IF } \\
\text { MSE } \\
\text { SNR }\end{array}$ & $\begin{array}{c}0.231 \\
0.224 \\
0.212 \\
0.24 \\
21.42\end{array}$ & $\begin{array}{l}0.473 \\
0.977 \\
0.813 \\
0.121 \\
33.28\end{array}$ & $\begin{array}{c}0.5023 \\
0.954 \\
0.889 \\
0.1012 \\
35.6\end{array}$ & $\begin{array}{c}0.4991 \\
0.971 \\
0.892 \\
0.1192 \\
37.41\end{array}$ & $\begin{array}{c}0.612 \\
0.977 \\
0.882 \\
1.02 \mathrm{E}-05 \\
78.8\end{array}$ & $\begin{array}{c}0.7731 \\
0.9001 \\
0.8835 \\
4.46 \mathrm{E}-06 \\
101.634\end{array}$ & $\begin{array}{c}0.79 \\
0.996 \\
0.929 \\
2.72 \mathrm{e}-005 \\
93.79\end{array}$ & $\begin{array}{l}-1 \text { to } 1 \\
-1 \text { to } 1 \\
0 \text { to } 1 \\
0 \text { to } 1 \\
-\infty \text { to } \infty\end{array}$ & $\begin{array}{c}\text { Closer to } 1 \\
\text { Closer to } 1 \\
\text { Closer to } 1 \\
\text { Closer to } 0 \\
\text { Possible Big }\end{array}$ \\
\hline B1S1 & $\begin{array}{c}\text { AD } \\
\text { MD } \\
\text { IF } \\
\text { MSE } \\
\text { SNR }\end{array}$ & $\begin{array}{l}0.342 \\
0.317 \\
0.391 \\
0.251 \\
3.241\end{array}$ & $\begin{array}{l}0.764 \\
0.819 \\
0.812 \\
0.228 \\
5.514\end{array}$ & $\begin{array}{c}0.7661 \\
0.919 \\
0.856 \\
1.34 \mathrm{e}-005 \\
32.154\end{array}$ & $\begin{array}{c}0.7015 \\
0.854 \\
0.876 \\
0.1759 \\
5.68\end{array}$ & $\begin{array}{c}0.794 \\
0.921 \\
0.898 \\
2.64 \mathrm{E}-005 \\
89.31\end{array}$ & $\begin{array}{c}0.6957 \\
0.815 \\
0.985 \\
4.62 \mathrm{E}-07 \\
111.482\end{array}$ & $\begin{array}{c}0.861 \\
935 \\
0.991 \\
7.87 \mathrm{e}-006 \\
99.173\end{array}$ & $\begin{array}{l}-1 \text { to } 1 \\
-1 \text { to } 1 \\
0 \text { to } 1 \\
0 \text { to } 1 \\
-\infty \text { to } \infty\end{array}$ & $\begin{array}{l}\text { Closer to } 1 \\
\text { Closer to } 1 \\
\text { Closer to } 1 \\
\text { Closer to } 0 \\
\text { Possible Big }\end{array}$ \\
\hline B1S2 & $\begin{array}{c}\text { AD } \\
\text { MD } \\
\text { IF } \\
\text { MSE } \\
\text { SNR }\end{array}$ & $\begin{array}{c}0.21 \\
0.21 \\
0.213 \\
0.06 \\
13.43\end{array}$ & $\begin{array}{c}0.3653 \\
0.892 \\
0.787 \\
0.145 \\
49.22\end{array}$ & $\begin{array}{c}0.654 \\
0.8825 \\
0.813 \\
0.096 \\
99\end{array}$ & $\begin{array}{l}0.232 \\
0.912 \\
0.791 \\
0.594 \\
20.39\end{array}$ & $\begin{array}{c}0.661 \\
0.921 \\
0.851 \\
0.024 \\
99\end{array}$ & $\begin{array}{c}0.4596 \\
0.891 \\
0.7893 \\
6.49 \mathrm{E}-06 \\
100.001\end{array}$ & $\begin{array}{c}0.712 \\
0.913 \\
0.958 \\
1.31 \mathrm{e}-006 \\
106.95\end{array}$ & $\begin{array}{l}-1 \text { to } 1 \\
-1 \text { to } 1 \\
0 \text { to } 1 \\
0 \text { to } 1 \\
-\infty \text { to } \infty\end{array}$ & $\begin{array}{l}\text { Closer to } 1 \\
\text { Closer to } 1 \\
\text { Closer to } 1 \\
\text { Closer to } 0 \\
\text { Possible Big }\end{array}$ \\
\hline B1S3 & $\begin{array}{c}\text { AD } \\
\text { MD } \\
\text { IF } \\
\text { MSE } \\
\text { SNR }\end{array}$ & $\begin{array}{c}0.323 \\
0.123 \\
0.233 \\
0.01 \\
11.11\end{array}$ & $\begin{array}{c}0.322 \\
0.212 \\
0.897 \\
0.4345 \\
27.267\end{array}$ & $\begin{array}{l}0.554 \\
0.413 \\
0.917 \\
0.002 \\
39.12\end{array}$ & $\begin{array}{c}0.4592 \\
0.456 \\
0.923 \\
0.119 \\
29.86\end{array}$ & $\begin{array}{c}0.54 \\
0.446 \\
0.926 \\
1.29 \mathrm{E}-005 \\
71.69\end{array}$ & $\begin{array}{c}0.4398 \\
0.546 \\
0.915 \\
2.62 \mathrm{E}-06 \\
103.95\end{array}$ & $\begin{array}{c}0.59 \\
0.596 \\
0.99 \\
2.16 \mathrm{e}-007 \\
114.78\end{array}$ & $\begin{array}{l}-1 \text { to } 1 \\
-1 \text { to } 1 \\
0 \text { to } 1 \\
0 \text { to } 1 \\
-\infty \text { to } \infty\end{array}$ & $\begin{array}{l}\text { Closer to } 1 \\
\text { Closer to } 1 \\
\text { Closer to } 1 \\
\text { Closer to } 0 \\
\text { Possible Big }\end{array}$ \\
\hline B1S4 & $\begin{array}{l}\text { AD } \\
\text { MD } \\
\text { IF } \\
\text { MSE } \\
\text { SNR }\end{array}$ & $\begin{array}{c}0.314 \\
0.241 \\
0.293 \\
0.18 \\
21.21\end{array}$ & $\begin{array}{l}0.338 \\
0.249 \\
0.683 \\
0.197 \\
78.19\end{array}$ & $\begin{array}{c}0.635 \\
0.294 \\
0.697 \\
0.113 \\
99\end{array}$ & $\begin{array}{c}0.497 \\
0.317 \\
0.791 \\
0.213 \\
99\end{array}$ & $\begin{array}{c}0.699 \\
0.391 \\
0.781 \\
0.829 \\
99\end{array}$ & $\begin{array}{c}0.521 \\
0.452 \\
0.8756 \\
3.83 \mathrm{E}-06 \\
102.2932\end{array}$ & $\begin{array}{c}0.732 \\
0.569 \\
1 \\
0.023 \\
106.26\end{array}$ & $\begin{array}{l}-1 \text { to } 1 \\
-1 \text { to } 1 \\
0 \text { to } 1 \\
0 \text { to } 1 \\
-\infty \text { to } \infty\end{array}$ & $\begin{array}{l}\text { Closer to } 1 \\
\text { Closer to } 1 \\
\text { Closer to } 1 \\
\text { Closer to 0 } \\
\text { Possible Big }\end{array}$ \\
\hline
\end{tabular}

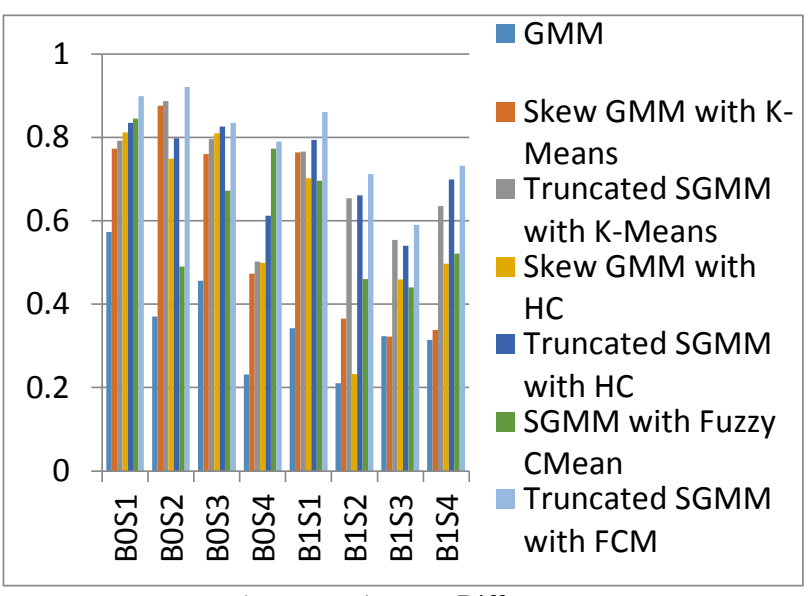

a) Average Difference

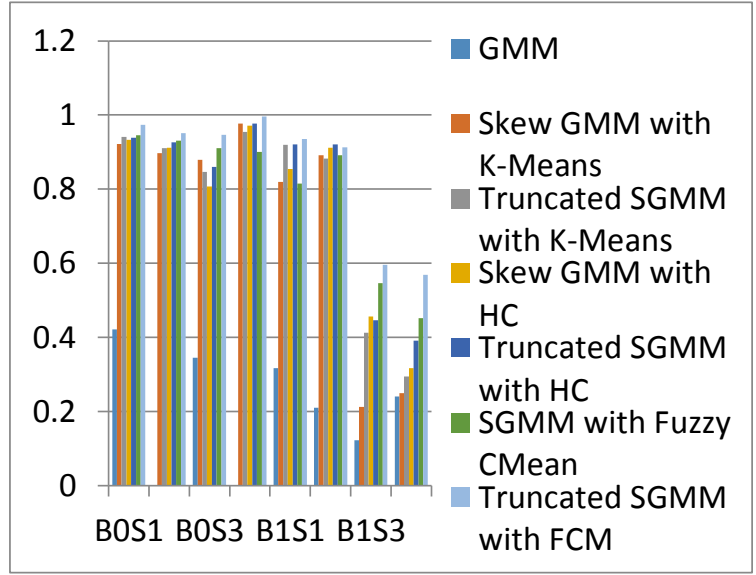

b) Maximum Distance 


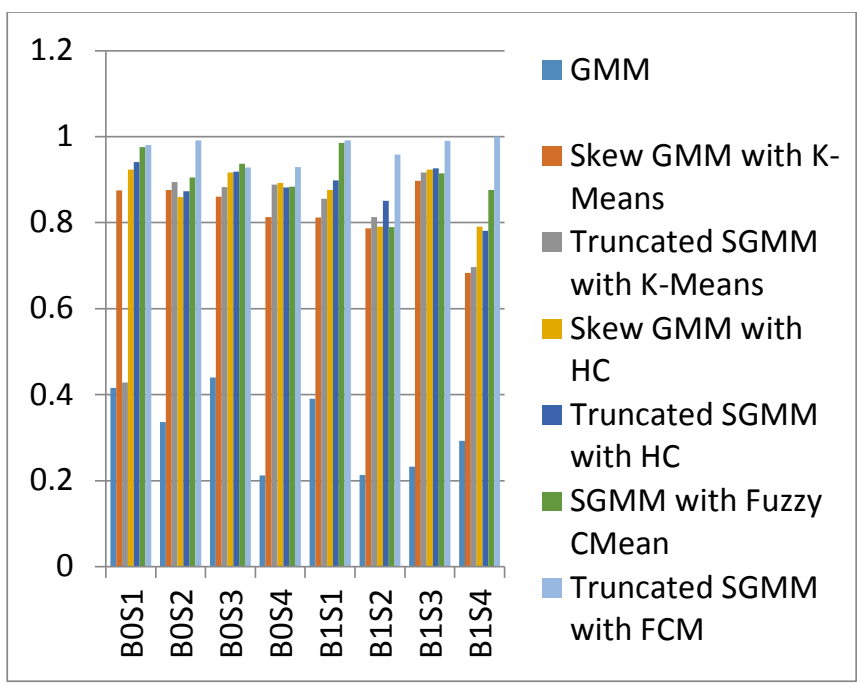

c) Image Fidelity
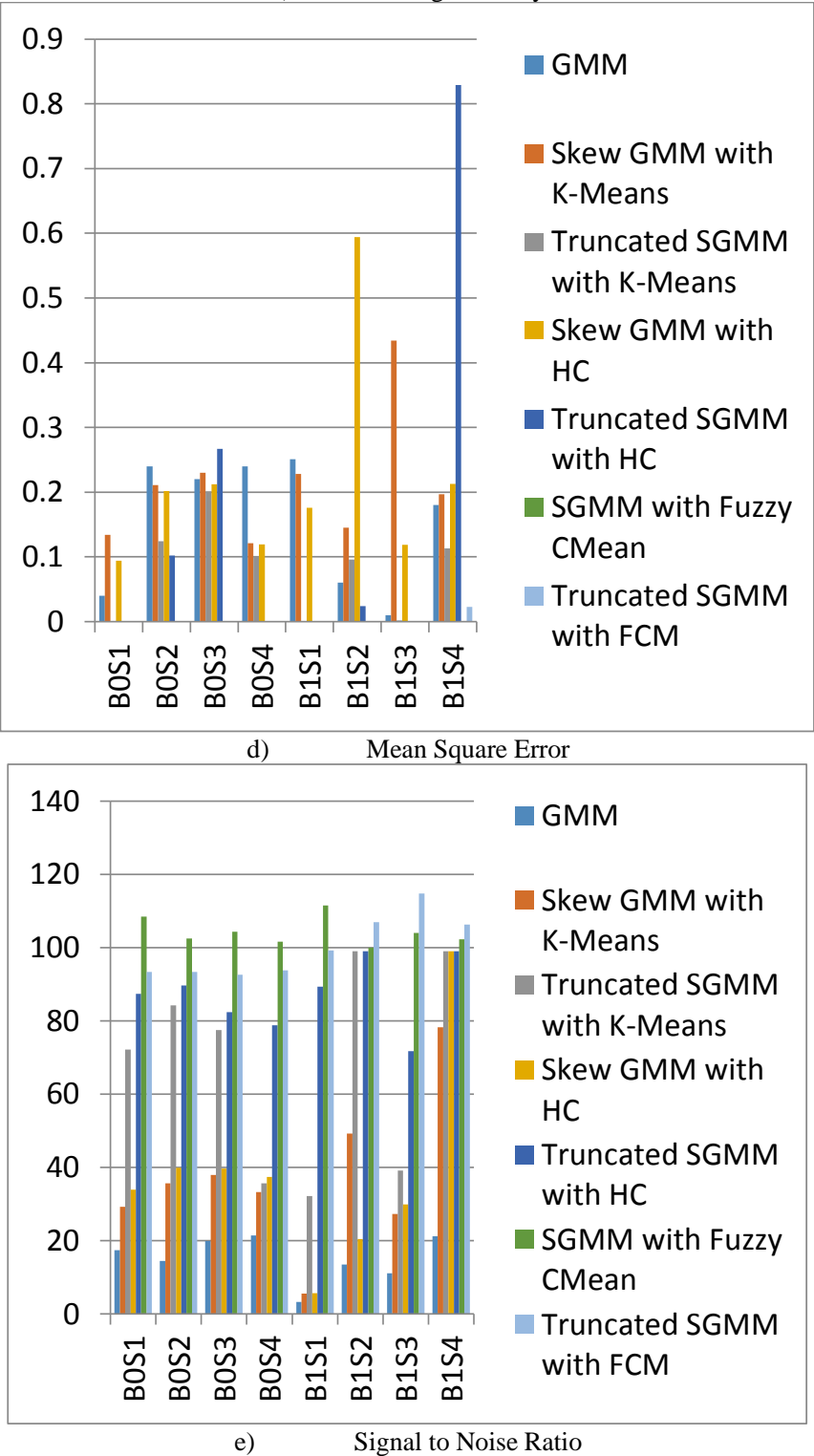

Fig. 2. Image Quality Metrics
The proposed method is compared to the methods based on Finite Gaussian Mixture Model, Finite Skew Gaussian Mixture Model with K - Means algorithms, Finite Skew Gaussian Mixture Model with Hierarchical Clustering algorithms and Finite Truncated Skew Gaussian Mixture Model with K Means and Hierarchical Clustering algorithms. The segmentation algorithm so developed is applied to 8 subimages as White Matter (WM), Gray Matter (GM), Cerebro Spinal Fluid (CSF) and Background of 2 brain images namely B0S1, B0S2, B0S3, B0S4, B1S1, B1S2, B1S3 and B1S4. The segmentation algorithm is developed and the performance of the segmentation algorithm is evaluated through segmentation quality metric such as jacquard Coefficient (JC), Volumetric Similarity (VS), Variation of Information (VOI), Global Consistency Error (GCE) and Probabilistic Random Index (PRI). The values after segmentation by using above quality metric are presented in Table-1. From the above table, for the medical image B0S1, the values of the JC and VS, the values of the developed method are close to 1 which implies that the segmentation methodology that is developed outperforming the segmentation model developed by using Gaussian Mixture Model and Finite Skew Gaussian Mixture model using KMeans algorithm. The other metrics such as VOI, GCE and PRI also are superior in the developed model when compared to the existing model for medical image segmentation based on medical image segmentation using Finite Truncated Skew Gaussian Mixture Models.

From the above tables- $1 \& 2$ and the fig. -1 and fig.- 2 , it is observed that the performance of medical image segmentation based on Finite Truncated Skew Gaussian Mixture Model using Fuzzy C-Means algorithm, the Average Difference (AD) for the image B0S1 is closure to 1 when compared to that of Gaussian Mixture Model, Skew Gaussian Mixture Model with K-Means, Hierarchical Clustering \& Fuzzy C-Means and Finite Truncated Skew Gaussian Mixture Model with K-Means \& Hierarchical Clustering algorithms. Similarly, the other quality metrics such as Maximum Distance (MD), Image Fidelity (IF), Mean Squared Error (MSE) and Signal to Noise Ratio (SNR) are more superior for the developed method than that of the model based on Gaussian Mixture Model. This can be clearly seen from the output images given in Graph-6.3. The same phenomenon is observed for the other medical images B0S1, B0S2, B0S3, B0S4, B1S1, B1S2, B1S3 and B0S4.

In all these images there is a drastic improvement in Image Quality metrics, the edges in medical image are more clearly visible. In the developed method, when compared to GMM, Skew GMM with K-Means, Hierarchical Clustering \& Fuzzy C-Means and Truncated Skew GMM with K-Means \& Hierarchical Clustering algorithms, the signal to noise ratio has increased and the Average Difference \& Image Fidelity are close to 1 and Mean Squared Error is close to 0 which implies that in the developed method, the edges are more closely visible and since MSE is much closure to 0, the output image is more closure to input image. Thus, the developed algorithm has the advantage that since the edges are much clearer, it gives a very comprehensive idea regarding the details of the medical images. The developed model helps to analyze the medical images in a better contrast than that of the existing models. 


\section{CONCLUSION}

This proposed article is focused towards MRI Brain Image Segmentation. A new approach based on Finite Truncated Skew Gaussian Mixture Model is introduced. The performance evaluation of the developed model is investigated by using Image quality metrics which depict that the developed algorithm outperforms the other existing algorithms based on Skew Gaussian mixture model using K-Means, Skew Gaussian mixture model Hierarchical Clustering, Skew Gaussian mixture model Fuzzy C-Means, Truncated Skew Gaussian mixture model with K-Means and Hierarchical Clustering algorithms and the results obtained showcase that the developed model has better segmentation accuracy. Effective segmentation helps in efficient identification of the damaged tissues much more effectively Therefore, the proposed method will be very much useful in diagnosing the diseases like acoustic neuroma, Alzheimer's, Parkinson's etc. more accurately.

\section{FUTURE SCOPE}

A methodology is presented for analyzing the brain images based on Truncated Gaussian Mixture models. However, to have a more precise segmentation, it is needed to consider the other features of the images also, which may include the shape, size, orientation and texture. Therefore, multivariate features should be considered to have a more detailed and effective analysis, further work is to be projected in this direction.

\section{REFERENCES}

[1] Vasant Manohar and Yuhua Gu: MRI Segmentation Using Fuzzy CMeans and Finite Gaussian Mixture Model, Digital Image Processing CAP5400, 2008.

[2] Z Y Shan, G H Yue and J Z Liu: Automated Histogram-Based Brain Segmentation in T1-Weighted Three-Dimensional Magnetic Resonance Head Images, NeuroImage v.17, pp. 1587-1598, 2002.

[3] G V S Raj Kumar, K Srinivasa Rao, and P Srinivasa Rao: Image Segmentation Method Based on Finite Doubly Truncated Bivariate Gaussian Mixture Model with Hierarchical Clustering, International Journal of Computer Science Issues, 8(4-2):151-159, July, 2011.

[4] Nagesh Vadaparthi, Srinivas Yerramalle, and Suresh Varma.P: Unsupervised Medical Image Segmentation on Brain MRI images using Skew Gaussian Distribution, IEEE - ICRTIT 2011, pp.1293 - 1297.

[5] Nagesh Vadaparthi, Srinivas Yerramalle, and Suresh Varma.P: Unsupervised Medical Image Classification based on Skew Gaussian Mixture Model and Hierarchical Clustering Algorithm" in CCIS of Springer-Links, Volume - 203, pp. 65-74, 2011.

[6] Nagesh Vadaparthi, Srinivas Yerramalle, and Suresh Varma.P: Segmentation of Brain MR Images based on Finite Skew Gaussian Mixture Model with Fuzzy C-Means Clustering and EM Algorithm", International Journal of Computer Applications, 28(10):18-26, August 2011.

[7] Nagesh Vadaparthi, Srinivas Yerramalle, and Suresh Varma.P: An Efficient Approach for Medical Image Segmentation Based on Truncated Skew Gaussian Mixture Model Using K-Means Algorithm”, International Journal of Computer Science and Telecommunications, (ISSN 2047-3338), 2(6):79-86, August 2011.
[8] Nagesh Vadaparthi, Srinivas Yerramalle, and Suresh Varma.P: On Improved Medical Brain MR Image Segmentation Based on Truncated Skew Gaussian Mixture Model using Hierarchical Clustering and EM algorithms", International Journal of Advanced Research in Computer Science (ISSN: 0976-5697), 2(6) November-December 2011.

[9] M. Sashidhar et al: MRI Brain Image Segmentation using Modified Fuzzy C-Means Clustering Algorithm, IEEE-Int. Conf. on Communication systems and Network Technologies, 2011, Pp.473-478.

[10] D. L. Pham, C. Y. Xu, and J. L. Prince: A survey of current methodsin medical image segmentation, Annu. Rev. Biomed. Eng., vol. 2, pp.315$337,2000$.

[11] K. Van Leemput, F. Maes, D. Vandeurmeulen, and P. Suetens: Automatedmodel-based tissue classification of MR images of the brain, IEEE Trans. Med. Imag., 18(10): 897-908, Oct. 1999.

[12] Dugas-Phocion, M. Á. González Ballester, G. Malandain, C. Lebrun and N. Ayache: Improved EM-based tissue segmentation andpartial volume effect quantification in multi-sequence brain MRI, Int. Conf. Med. Image Comput. Comput. Assist. Int. (MICCAI), 2004, pp. 26-33.

[13] K. Van Leemput, F. Maes, D. Vandermeulen, and P. Suetens: A unifying framework for partial volume segmentation of brainMR Images, IEEE Trans. Med. Imag., 22(1):105-119, Jan. 2003.

[14] M. Prastawa, E. Bullitt, S. Ho, and G. Gerig: Robust estimation forbrain tumor segmentation, Int. Conf. Med. Image Comput. Comput.Assist. Inter (MICCAI), 2003, pp. 530-537.

[15] Lee TI, Maximum likelihood estimation for multivariate skew normal mixture models, Journal of Multivariate Analysis 100 (2009) 257-265, 2009.

[16] Cabral CS, Lachos VH, Prates MO, Multivariate mixture modeling using skew-normal independent distributions. Computational Statistics and Data Analysis 56:126-142, 2012.

[17] Lee TI, Robust mixture modeling using multivariate skew distributions, stat comp (2010) 20:343-356, DOI 10.1007/s I 1222-009-9128-9, 2010.

[18] Lee S, McLachlan GJ, On the fitting of mixtures of multivariate skew tdistributions via the EM algorithm. arXiv:11094706 [statME], 2011.

[19] Vrbik I, McNicholas PD, Analytic calculations for the EM algorithm for multivariate skew t-mixture models. Statistics and Probability Letters, 32 Sharon X. Lee, Geoffrey J. McLachlan 82:1169-1174, 2012.

[20] Lin TI, Ho HJ, Kee CR, Flexible mixture modelling using the multivariate skew-t-normal distribution. Statistics and Computing DOI 10.1007/s11222-013-9386-4, 2013.

[21] Karlis D, Xekalaki E, Choosing initial values for the EM algorithm for finite mixtures. Computational Statistics \& Data Analysis 41:577-590, 2003

[22] Franczak BC, Browne RP, McNicholas PD, Mixtures of shifted asymmetric laplace distributions. arXiv:12071727 [statME], 2012.

[23] McNeil AJ, Frey R, Embrechts P, Quantitative risk management : concepts, techniques and tools. Princeton University Press, USA, 1997.

[24] Embrechts, P., Kl"uppelberg, C., and Mikosch, T., Modelling Extremal Events for Insurance and Finance. Springer-Verlag, New York, 1997.

[25] Burnecki, K., Misiorek, A., and Weron, R., Loss distributions. In Statistical Tools for Finance and Insurance. Cizek, P., H“ardle, W. K., and Weron, R. Eds. Springer-Verlag.2010.

[26] Sylvain Bouix et al.: Evaluating Brain Tissue Classifiers without a ground truth, Journal of NeuroImage (ELSEVIER) - 36, pp. 1207 1224, 2007.

[27] Ahmet M. Eskicioglu and Paul S. Fisher: Image Quality Measures and Their Performance, IEEE Transactions on Communications, 43(12):2959 - 2965, Dec.1995. 